\title{
REVISÃO DO GÊNERO NATAGAIMA (COLEOPTERA, CERAMBYCIDAE, LAMIINAE)
}

\author{
Carlos Eduardo de Alvarenga Julio",
}

\begin{abstract}
REVISION OF THE GENUS NATAGAIMA (COLEOPTERA, CERAMBYCIDAE, LAMIINAE). Natagaima Lane, 1972 is revised and provisionally transferred from Anisocerini to Acanthoderini. The genus and the type species, Natagaima balteata Lane, 1972, are redescribed and two new species added: N. moacyri, from Colombia (Tumaco) and N. heloisae, from Ecuador (Napo). All the species are illustrated and keyed.

KEYWORDS. Cerambycidae, Acanthoderini, Natagaima, taxonomy, Neotropical.

\section{INTRODUÇÃO}

LANE (1972) erigiu o gênero Natagaima para N. balteata procedente da Colômbia e Guatemala. Comentou que "este gênero apresenta caracteres dos Acanthoderini, mas no conjunto dos seus elementos opto em colocá-lo entre os Anisocerini".

O exame de material pertencente às coleções do Museu Nacional, Universidade Federal do Rio de Janeiro (MNRJ) e Museu de Zoologia, Universidade de São Paulo (MZSP) permitiu propor a transferência de Natagaima para a tribo Acanthoderini e descrever duas espécies da Colômbia e Equador. Foram incluídas a redescrição de $N$. balteata e chave para identificação das espécies.
\end{abstract}

\section{Natagaima Lane, 1972}

Natagaima LANE, 1972:367; MonNÉ, 1994:5 (cat.).

Espécie-tipo, Natagaima balteata Lane, 1972 (monotipia e designação original).

\footnotetext{
1. Departamento de Entomologia, Museu Nacional, Universidade Federal do Rio de Janeiro, Quinta da Boa Vista, São Cristóvão, 20940-040, Rio de Janeiro, RJ, Brasil. (ceajulio@ig.com.br)

2. Doutorando em Ciências Biológicas, Zoologia, Instituto de Biociências, Universidade Estadual Paulista, Botucatu.
} 
Fronte plana, finamente pontuada, com os lados paralelos e borda inferior arqueada; área entre os tubérculos anteníferos com ou sem pontuação profunda e esparsa. Olhos pequenos, divididos, com apenas um filete sem omatídios unindo os lobos oculares inferior e superior; lobos oculares superiores tão distantes entre si quanto o dobro da largura de um lobo. Tubérculos anteníferos separados entre si e não projetados. Antenas com onze artículos, nos machos tão ou um pouco mais longas que o corpo e, nas fêmeas, não alcançam o ápice elitral; escapo clavado, mais robusto nos machos, pouco adelgaçado na base; antenômero III, não modificado, pouco mais longo que o escapo nos machos e subigual nas fêmeas; antenômero IV tão longo quanto o III, com uma lamela apical expandida para os dois lados; antenômeros V-XI gradualmente decrescentes em comprimento.

Protórax mais largo que longo, com tubérculo lateral rombo manifesto; pronoto com elevações oblíquas látero-anteriores e longitudinal central, desenvolvidas ou não; margens anterior e posterior com pontuação profunda; cavidades procoxais não angulosas externamente; processo prosternal arqueado. Processo mesosternal bituberculado e truncado na margem posterior; cavidades mesocoxais fechadas. Élitros densa e profundamente pontuados no terço basal, com crista longitudinal centro-basal manifesta; planos nos $2 / 3$ basais e em declive e convexos no terço apical; lados subparalelos até o meio e gradualmente estreitados para os ápices, estes reta ou obliquamente truncados; úmeros arredondados, com ou sem grânulos. Fêmures pedunculados, os anteriores mais robustos; protíbias aplanadas e alargadas para o lado externo do ápice; protarsos franjados nos machos.

Urosternito $\mathrm{V}$ das fêmeas tão longo quanto os três anteriores reunidos, com pequeno sulco no centro da metade basal.

Comentários. Os olhos divididos por apenas um filete, sem omatídios; o aspecto oblíquo das elevações látero-anteriores do pronoto; as cavidades procoxais nãoangulosas externamente e as mesocoxais fechadas; os élitros planos nos $2 / 3$ basais e em declive e convexos no terço apical, com os lados subparalelos até o meio, gradualmente estreitados para os ápices; e os ápices elitrais truncados, permitem posicionar, provisoriamente, Natagaima na tribo Acanthoderini. Assemelha-se a Scleronotus, proposto por White (1855), pelos olhos divididos, com apenas um filete unindo os lobos inferior e superior; pelo aspecto do tubérculo lateral do protórax rombo e das elevações látero-anteriores do pronoto oblíquas e pelo formato dos élitros, planos nos $2 / 3$ basais e em declive e convexos no terço apical, com os lados subparalelos até o meio, gradualmente estreitados para os ápices, estes retos ou obliquamente truncados. Distingue-se pelos antenômeros III e IV com o mesmo comprimento, o IV com lamela apical expandida para os dois lados; pelo aspecto da superfície elitral com densa pontuação profunda no terço basal, sem grânulos ou tufos de cerdas e pelo aspecto da crista centro-basal dos élitros, longitudinal, alongada desde a margem até aproximadamente o quarto basal. Em Scleronotus: antenômero III com uma vez e meia o comprimento do IV, este não-modificado; superfície elitral recoberta por grânulos ou tufos de cerdas; élitros com gibosidade centro-basal curta, elevada, com grânulos ou tufos de cerdas no topo. 


\section{Chave para as espécies de Natagaima}

1. Tegumento castanho-avermelhado; pronoto com desenho triangular no centro do disco, formado por pubescência decumbente esbranquiçada, o vértice do triângulo tocando a margem anterior; elevações pronotais discretas, pouco manifestas; élitros com a metade basal recoberta por pubescência decumbente castanhoclara, delimitada no centro por estreita faixa oblíqua esbranquiçada que toca os lados do disco e a sutura um pouco além do meio, terço apical recoberto por pubescência decumbente castanho-clara com máculas castanho-escuras, delimitada por faixa transversal branca e área entre as faixas oblíqua e transversal revestida por pubescência castanho-escura; ápices elitrais retamente truncados; protíbias bruscamente dilatadas e aplanadas nos $2 / 3$ apicais. Fêmea (fig. 1). Guatemala e Colômbia . N. balteata Lane, 1972

Tegumento negro; pronoto sem desenho, revestido por rala pubescência castanhoescura ou por densa pubescência decumbente branca em área central do disco; gibosidades pronotais látero-anteriores oblíquas desenvolvidas e calo central manifesto; élitros sem desenhos, revestidos por rala pubescência castanho-escura ou por pubescência branca, amarela e castanho-escura mescladas; ápices elitrais obliquamente truncados; protíbias gradualmente dilatadas e aplanadas a partir da base

2. Superfície corporal revestida, em sua maior parte, por rala pubescência castanhoescura; antenas, nos machos, com o comprimento subigual ao do corpo; escapo scavado na face dorsal da base; antenômeros VI-IX sem modificação ventral; élitros com pontuação profunda e esparsa no terço basal, com os $2 / 3$ apicais lisos, não-pontuados exceto a crista centro-basal pontuada no topo; processo mesosternal com tubérculos protuberantes. Macho (fig. 2). Colômbia (Tumaco) N. moacyri sp. nov.

Genas, escapo, pedicelo, antenômero III, metade basal do IV, pernas e a superfície ventral do corpo recobertos por flocos de pubescência esbranquiçada, área central do pronoto e região basal dos élitros próxima às cristas centro-basais com densa pubescência decumbente branca e o restante dos élitros revestido por pubescência branca, amarelada e castanho-escura mescladas; antenas, nos machos, ultrapassam os ápices elitrais; escapo não-escavado na face dorsal da base; antenômeros VIIX com pequena cicatriz ventral; élitros densamente granulado-pontuados na metade basal e crista com granulação no topo; processo mesosternal com tubérculos discretos. Macho (fig. 3). Equador (Napo) N. heloisae sp. nov.

\section{Natagaima balteata Lane, 1972}

(Fig. 1)

Natagaima balteata Lane, 1972:368, fig. 2; MonNÉ, 1994:5 (cat.).

$\therefore$ Tegumento castanho-avermelhado. Cabeça revestida por pubescência esbranquiçada rala; fronte finamente pontuada, área entre os tubérculos anteníferos com pontuação esparsa mais profunda. Antenas com comprimento subigual ao do corpo; escapo com pequena escavação na face dorsal da base; antenômero III um pouco mais 
longo que o escapo, tão longo quanto o IV, com pequenas cerdas eretas e esparsas na face ventral; antenômeros IV-XI recobertos por pubescência esbranquiçada na metade basal, o IV com lamela apical castanho-escura expandida para os dois lados e com densas cerdas eretas na face interna do lado ventral; V-XI gradualmente decrescentes em comprimento.

Pronoto com desenho triangular no centro, formado por pubescência decumbente esbranquiçada, o vértice do triângulo tocando a margem anterior, e área interna revestida por pubescência rala castanho-clara e pontuação profunda; área externa ao desenho e lados do protórax recobertos por pubescência castanho-escura; elevações pronotais discretas, pouco manifestas. Élitros densa e profundamente pontuados no terço basal; metade basal recoberta por pubescência decumbente castanho-clara, delimitada, no centro, por estreita faixa oblíqua esbranquiçada que toca os lados do disco e a sutura um pouco além do meio; terço apical recoberto por pubescência decumbente castanho-clara, com máculas castanho-escuras, delimitada por faixa transversal branca; área entre as faixas oblíqua e transversal revestida por pubescência castanho-escura; crista centro-basal discreta; úmeros não-granulados e ápices retamente truncados. Protíbias bruscamente dilatadas e aplanadas nos $2 / 3$ apicais; protarsos com franjas laterais negras.

Superfície ventral do corpo recoberta por pubescência decumbente castanho-clara.

(fig. 1). Antenas atingem, aproximadamente, o meio dos élitros; escapo nãoescavado na face dorsal da base, esbelto e pouco adelgaçado na base; antenômero III subigual ao escapo em comprimento. Urosternito $\mathrm{V}$ com pequeno sulco no centro da metade apical.

Dimensões $(\mathrm{mm})$ respectivamente ' e Comprimento total 8,9 e 9,0; protórax, comprimento 2,1 e 2,1, maior largura, 3,3 e 3,4; comprimento do élitro 5,6 e 5,8; largura umeral 3,8 e 4,2 .

Material examinado. COLÔMBIA, Tolima: Natagaima, parátipo '-, Tippmann col. (MZSP); Cauca: Santa Rosa, !', VIII.1878, Eujenio Garzon col. (MNRJ).

\section{Natagaima moacyri sp. nov.}

(Fig. 2)

Etimologia. Espécie dedicada a Moacyr Alvarenga.

$\checkmark$ (fig. 2). Tegumento negro. Metade basal dos antenômeros IV-XI castanho-clara; pernas castanho-avermelhadas. Maior parte da superfície corporal recoberta por pubescência castanho-escura. Fronte finamente pontuada; área entre os tubérculos anteníferos sem pontuação profunda. Antenas com comprimento subigual ao do corpo; escapo escavado na face dorsal da base; antenômero III um pouco mais longo que o escapo, com cerdas eretas e esparsas na face ventral; lamela do antenômero IV com cerdas curtas na face interna do lado ventral; antenômeros IX-XI com setas eretas na face ventral.

Pronoto com elevações látero-anteriores oblíquas desenvolvidas e pequeno calo central manifesto; processo mesosternal com tubérculos desenvolvidos. Terço basal dos élitros com pontuação profunda esparsa, os $2 / 3$ apicais lisos, não-pontuados; crista centrobasal um pouco elevada e pontuada; úmeros não-granulados; ápices obliquamente truncados. Protíbias gradualmente aplanadas e dilatadas a partir da base; franjas laterais dos protarsos negras; meso- e metatarsos recobertos por densa pubescência decumbente esbranquiçada. 

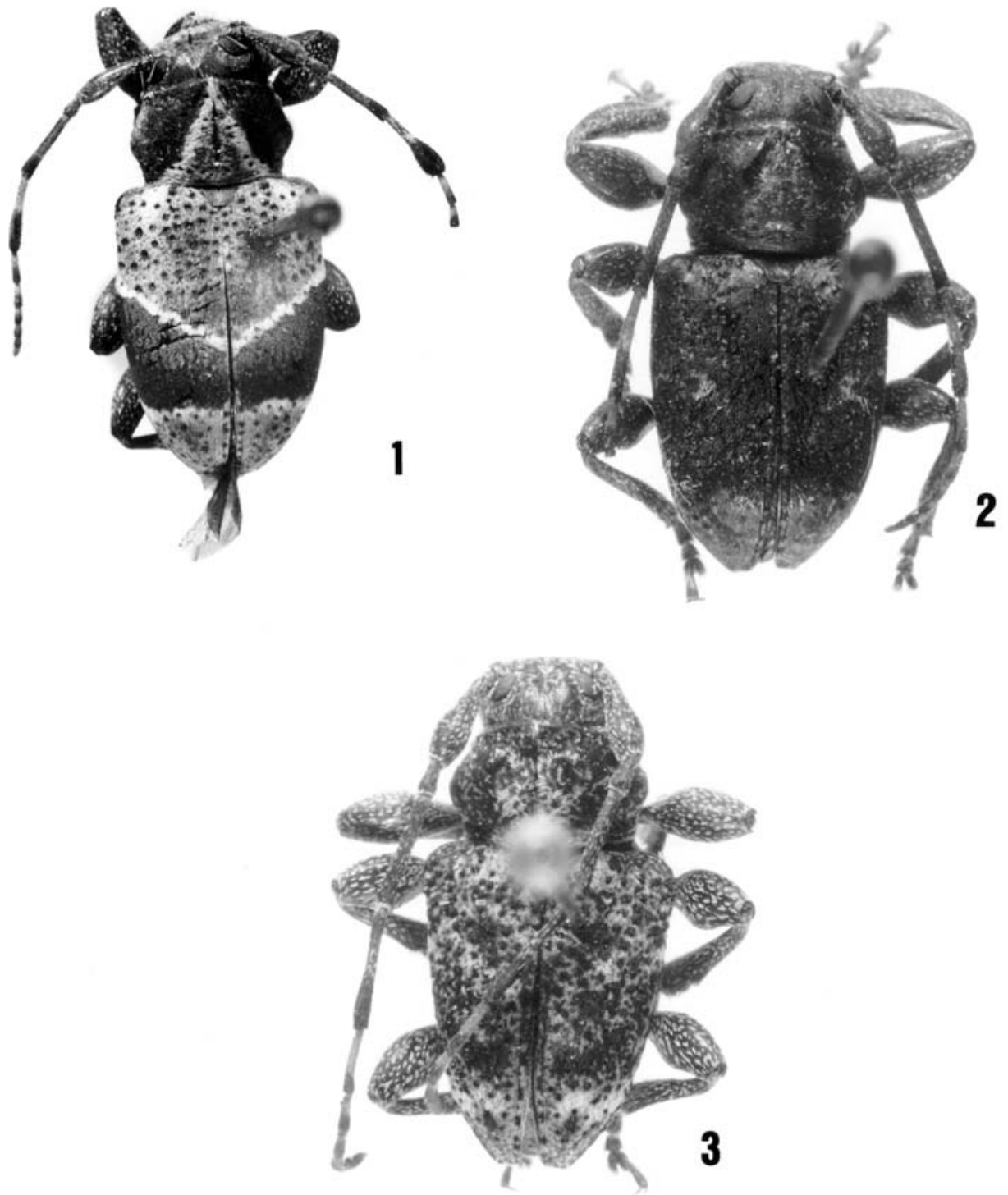

Figs. 1-3. 1, Natagaima balteata Lane, 1972: parátipo - (MZSP), Natagaima, Tolima, Colômbia, comprimento 9,0 mm; 2, Natagaima moacyri sp. nov.: holótipo '’ (MNRJ), Tumaco, Nariño, Colômbia, comprimento 9,2 mm; 3, Natagaima heloisae sp. nov.: holótipo ‘'(MNRJ), Coca, Napo, Equador, comprimento $8,5 \mathrm{~mm}$. 
Dimensões (mm). Comprimento total 9,2; protórax, comprimento 2,2, maior largura, 3,6; comprimento do élitro 5,9; largura umeral 4,2.

Material-tipo. Holótipo ‘, COLÔMBIA, Nariño: Tumaco, 12.IV.58, Steinh col. (MNRJ).

\section{Natagaima heloisae sp. nov.}

(Fig. 3)

Etimologia. Espécie dedicada a Heloisa Helena de F. Alvarenga.

(fig. 3). Tegumento predominantemente castanho-escuro. Flocos de pubescência esbranquiçada recobrem a gena, escapo, pedicelo, antenômero III, metade apical do IV, pernas e superfície ventral do corpo; área central do pronoto e região basal dos élitros próxima às cristas centro-basais com densa pubescência decumbente branca; restante dos élitros revestido por pubescência branca, amarelada e castanho-escura mescladas. Fronte finamente pontuada, com flocos de pubescência esbranquiçada e amarelada mescladas; área entre os tubérculos anteníferos sem pontuação profunda, um pouco escavada no centro. Antenas ultrapassam o ápice elitral por três antenômeros; escapo sem escavação na face dorsal da base; antenômeros III e IV com cerdas eretas na face ventral, mais concentradas no III; antenômeros V-VIII castanho-claros nos 2/3 basais; VIIX com pequena cicatriz ventral; IX-XI com setas na face ventral.

Pronoto com gibosidades oblíquas látero-anteriores e calo central desenvolvidos; processo mesosternal com tubérculos discretos. Élitros granulado-pontuados, mais densamente na metade basal; crista centro-basal desenvolvida, granulada no topo; úmeros esparsamente granulados; ápices obliquamente truncados. Protíbias gradualmente aplanadas e dilatadas a partir da base; protarsos com franjas laterais negras; meso- e metatarsos recobertos por densa pubescência decumbente branca.

Dimensões (mm). Comprimento total 8,5; protórax, comprimento 2,0, maior largura, 3,4; comprimento do élitro 5,5; largura umeral 4,1.

Material-tipo. Holótipo '‘, EQUADOR, Napo: Coca, V.1985, G. Onore col. (MNRJ).

Comentários. Assemelha-se e distingue-se de N. moacyri pelos caracteres arrolados na chave.

Agradecimentos. Ao Dr. Miguel A. Monné (MNRJ) pelas sugestões e revisão do manuscrito; ao Dr. Ubirajara R. Martins (MZSP) pelo empréstimo de material; a Sérgio Barbosa Gonçalves pela execução das fotografias e a Fundação de Amparo à Pesquisa do Estado de São Paulo (FAPESP, Proc. $\mathrm{n}^{\circ}$ 98/10692-5) pela bolsa de Doutorado concedida.

\section{REFERÊNCIAS BIBLIOGRÁFICAS}

LANe, F. 1972. Cerambycoidea neotropica nova VIII (Coleoptera). Studia ent., Petrópolis, 15(14):353-382.

Monné, M. A. 1994. Catalogue of the Cerambycidae (Coleoptera) of the Western Hemisphere. Part XVII. São Paulo, Sociedade Brasileira de Entomologia. 110 p.

White, A. 1855. Catalogue of the coleopterous insects in the collection of the British

Museum. Part VIII. Longicornia 2. London, British Museum. p.175-412.

Recebido em 15.04.2002; aceito em 05.12.2002. 